\title{
Endoscopic endonasal transclival transodontoid approach for ventral decompression of the craniovertebral junction: operative technique and nuances
}

\author{
James K. Liu, MD, ${ }^{1-3}$ Jimmy Patel, BS, Ira M. Goldstein, MD,, and Jean Anderson Eloy, MD ${ }^{1-3}$ \\ Departments of ${ }^{1}$ Neurological Surgery and ${ }^{2}$ Otolaryngology-Head and Neck Surgery, ${ }^{3}$ Center for Skull Base and Pituitary \\ Surgery, Neurological Institute of New Jersey, Rutgers New Jersey Medical School, Newark, New Jersey
}

\begin{abstract}
The transoral approach is considered the gold-standard surgical route for performing anterior odontoidectomy and ventral decompression of the craniovertebral junction for pathological conditions that result in symptomatic cervicomedullary compression, including basilar invagination, rheumatoid pannus, platybasia with retroflexed odontoid processes, and neoplasms. Extended modifications to increase the operative corridor and exposure include the transmaxillary, extended "open-door" maxillotomy, transpalatal, and transmandibular approaches. With the advent of extended endoscopic endonasal skull base techniques, there has been increased interest in the last decade in the endoscopic endonasal transclival transodontoid approach to the craniovertebral junction. The endonasal route represents an attractive minimally invasive surgical alternative, especially in cases of irreducible basilar invagination in which the pathology is situated well above the palatine line. Angled endoscopes and instrumentation can also be used for lower-lying pathology. By avoiding the oral cavity and subsequently using a transoral retractor, the endonasal route has the advantages of avoiding complications related to tongue swelling, tracheal swelling, prolonged intubation, velopharyngeal insufficiency, dysphagia, and dysphonia. Postoperative recovery is quicker, and hospital stays are shorter. In this report, the authors describe and illustrate their method of purely endoscopic endonasal transclival odonotoidectomy for anterior decompression of the craniovertebral junction and describe various operative pearls and nuances of the technique for avoiding complications. http://thejns.org/doi/abs/10.3171/2015.1.FOCUS14813
\end{abstract}

KEY WORDS endoscopic endonasal transclival transodontoid approach; transnasal odontoidectomy; basilar invagination; craniovertebral junction; endoscopic skull base surgery

$\mathrm{V}$ ARIOUS abnormalities of the craniocervical junction can result in ventral compression of the cervicomedullary junction and require anterior decompression, including resection of the $\mathrm{C}-1$ arch and odontoidectomy. ${ }^{14}$ Several indications for anterior decompression and odontoidectomy include irreducible basilar invagination, ${ }^{13,17,22,26,27,34,50,52,53}$ severe compressive rheumatoid pannus not resolved by posterior stabilization,,$^{14,40,51}$ os odontoideum, ${ }^{29,32}$ and severely retroflexed odontoid processes associated with Chiari malformation Type I. ${ }^{21}$

The transoral approach has been the accepted workhorse and gold standard for anterior decompression of the craniocervical junction for the last several decades., ${ }^{3,5}$,
7-10,17,20,30,35-37,39,47 This approach provides the most direct anterior route to the ventral craniocervical junction. In some cases, extended modifications, such as the transmaxillary (Le Fort I maxillotomy) approach, transmaxillary palatal split (extended "open-door" maxillotomy) approach, transpalatal approach, or median labiomandibular glossotomy (transmandibular split) approach, may be necessary to access lesions that extend beyond the exposure limits of a standard transoral approach. ${ }^{30}$ These transoral approaches can be associated with significant morbidity. Splitting of the soft palate and resection of the hard palate can increase the risk of hypernasal speech and nasal regurgitation from velopharyngeal insufficiency. The use 
of a transoral retractor can result in postoperative tongue swelling, prolonged intubation, tracheal swelling, and poor feeding and, thus, can necessitate postoperative tracheostomy and gastrostomy. Craniofacial disassembly with maxillary, mandibular, and glossal splitting can be cosmetically unappealing and associated with increased morbidity and prolonged hospitalization.

The advent of endoscopic endonasal skull base techniques has enabled safe and effective access to the ventral skull base and craniovertebral junction. The endoscopic approach provides increased illumination that can be brought up close to the deep surgical target, and it provides a wider panoramic view. These advantages can reduce the need for a wide operative approach. ${ }^{18,28}$ Because the incision is made above the oropharynx and the oral cavity can be avoided without a transoral retractor or splitting of the soft palate, the endoscopic endonasal approach avoids the risk of tongue compression and subsequent swelling, tracheal swelling, velopharyngeal insufficiency, infection, and swallowing and breathing difficulties. $18,43,49$ Postoperative recovery after endonasal skull base surgery is generally quicker, the hospital stays are shorter, and patients are fed orally and ambulate earlier in the postoperative period than patients who undergo transoral procedures. . $^{6,14,18,43}$

The endoscopic endonasal approach for odontoidectomy has been investigated in cadaveric studies and in several clinical studies. ${ }^{2,4,6,14,18,23,24,28,32,33,38,40-46,48}$ Although several variations in technique exist in the literature, the aims of this report are to describe our method of the purely endoscopic endonasal transclival transodontoid approach for anterior decompression of the craniovertebral junction and to describe various operative pearls and nuances of the technique.

\section{Preoperative Considerations \\ Neuroimaging}

Careful review of radiographic images of the craniovertebral junction, including MR and CT images, is paramount before selecting an endoscopic endonasal approach. The relationship of the odontoid process relative to the Chamberlain line (a line that joins the back of the hard palate with the posterior lip of the foramen magnum on a lateral view of the craniocervical junction) is used to determine the extent of basilar invagination. Basilar invagination is present if $>3 \mathrm{~mm}$ of the odontoid is above this line. The palatine line (a line drawn along the plane of the hard palate toward the craniovertebral junction on a sagittal CT image) is very helpful in determining the feasibility of the endonasal approach. ${ }^{15}$ If the compressive lesion is above the palatine line, an endonasal approach is the preferred approach, because the surgical working corridor is above the plane of the hard palate.

However, if the lesion extends below the palatine line, an endonasal route is not necessarily contraindicated. Several authors have proposed various methods of predicting the inferior limit of the endonasal approach by drawing anatomical lines on sagittal CT scans. ${ }^{1,12}$ The nasopalatine line (Kassam line) was previously proposed to predict this inferior limit by drawing a line from the rhin- ion toward the posterior edge of the hard palate that continues toward the craniovertebral junction. ${ }^{12}$ However, the nasopalatine line seems to overestimate the inferior limit of the approach by approximately $6-12 \mathrm{~mm}{ }^{1}$ The trajectory and angle of this line are often too steep and are not reproducible in clinical settings, because the line does not take into account the soft tissue limitations of the nare. To provide an alternative, Aldana et al. ${ }^{1}$ described the nasoaxial line, which is drawn from the midpoint between the rhinion and the anterior nasal spine that extends toward the posterior edge of the hard palate and continues toward the craniovertebral junction. In their cadaveric study, the nasoaxial line was more accurate in predicting the inferior limit of the endonasal endoscopic approach than the nasopalatine line. Figure 1 shows the different anatomical lines drawn on several different patients to predict the inferior limit of the approach. In our practice, we generally use the palatine line and the nasoaxial line to determine the optimal surgical approach. If the lesion extends beyond the reach of the nasoaxial line, a transoral approach (which can be performed endoscopically as an endoscopic transoral approach) can be used alone or in combination with the endoscopic endonasal approach, if needed.

In addition, preoperative dynamic plain radiographs in flexion and extension views should be obtained to assess
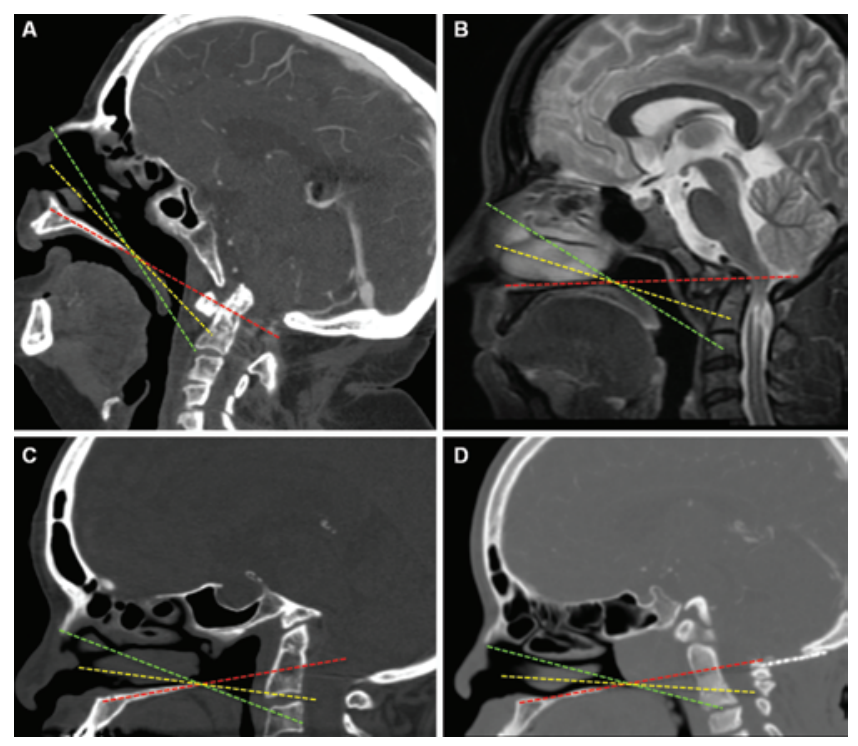

FIG. 1. Anatomical lines drawn on sagittal CT or MR images in patients with basilar invagination to assess the feasibility of the endoscopic endonasal approach and to determine the inferior limit of the approach. The palatine line (red dotted line) is a line drawn along the plane of the hard palate toward the craniovertebral junction. If the odontoid lies above the palatine line, an endoscopic endonasal approach can be performed. If, however, the compressive lesion lies below the palatine line, the nasoaxial line (yellow dotted line) is drawn. The initial starting point is the midpoint between the rhinion and the anterior nasal spine, and a line is drawn to intersect the posterior edge of the hard palate and continues toward the craniovertebral junction. This line more accurately predicts the inferior limit of the endoscopic endonasal approach. The nasopalatine line (green dotted line), which starts at the rhinion and intersects the posterior edge of the hard palate and continues toward the upper cervical spine, tends to overestimate the inferior limit of the endonasal approach. In all 4 patients shown here, surgery via the endoscopic endonasal approach was performed successfully, and the nasoaxial line accurately predicted the inferior limit of the approach. 
for preexisting instability at the craniovertebral junction. Even if there is no instability present, most patients will require posterior occipitocervical stabilization and fusion because of iatrogenic instability after resection of the odontoid and involved ligaments.

\section{Cervical Traction}

Patients with basilar invagination, severe deformity, or cranial settling are admitted to the hospital and placed in cervical traction using Gardner-Wells tongs to determine if the deformity can be reduced. If reduction to an anatomical position sufficient to decompress the neural elements can be achieved, posterior occipitocervical stabilization and fusion are performed initially. ${ }^{16,30}$ In patients with rheumatoid arthritis, the compressive soft-tissue pannus will generally resolve after occipitocervical fusion. ${ }^{14}$ If, however, the basilar invagination is irreducible and/ or there is persistent symptomatic ventral compression of the cervicomedullary junction by the odontoid process or soft-tissue pannus, an anterior odontoidectomy and decompression of the craniovertebral junction are warranted. In cases of irreducible basilar invagination, we generally prefer first to perform an endoscopic endonasal odontoidectomy, followed by posterior occipitocervical stabilization in a staged fashion (within 48 hours).

\section{Surgical Technique Patient Positioning}

Before the induction of general anesthesia, the patient undergoes fiber-optic intubation, and motor function is assessed. The endotracheal tube is secured with the tube exiting the left lower corner of the mouth. Continuous blood pressure monitoring is performed with an arterial line. The patient is placed in the supine position with his or her head secured in a Mayfield 3-pin fixation system in the neutral position (Fig. 2). Gentle traction can be applied to the head holder to facilitate some decompression of the cervicomedullary junction. However, application of flexion or extension during positioning should be avoided, because it may result in worsening brainstem or spinal cord compression. The patient is secured to the table with adhesive tape to allow for safe tilting of the table during surgery, if needed. Intraoperative neuromonitoring of somatosensory evoked potentials, motor evoked potentials, and bilateral brainstem auditory evoked responses are used to assess intraoperative spinal cord and brainstem function.

Intraoperative fluoroscopy can be used, if needed, to verify the alignment of the craniocervical junction and to

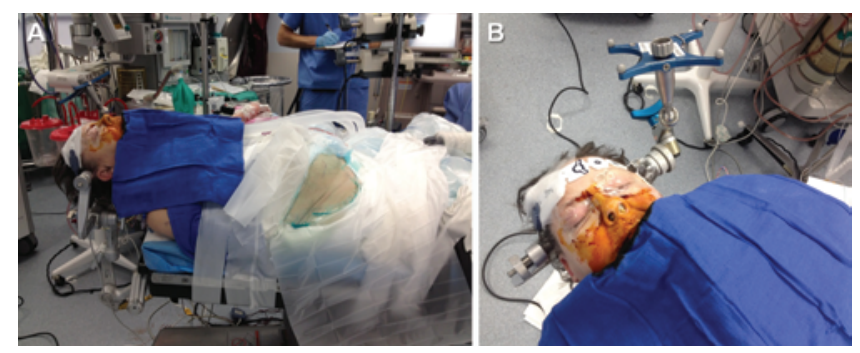

FIG. 2. Surgical positioning and set up for the endoscopic endonasal transclival transodontoid approach to the craniovertebral junction. assess the extent of ventral decompression intraoperatively. We routinely use intraoperative stereotactic navigation using high-resolution $\mathrm{CT}$ angiography images, which provide better visual resolution of bony structures (hard palate, clivus, $\mathrm{C}-1$ arch, odontoid) and neighboring vascular structures (the vertebrobasilar arterial system). If desired, MR images can be fused with the CT angiogram images for navigation.

The patient's nose and nares are prepared with Betadine solution, followed by placement of Afrin-soaked cottonoid pledgets into the nasal cavity to promote vasoconstriction and decongestion of the nasal mucosa. The patient's abdomen and right thigh are prepared for fat graft and/or fascia lata graft harvesting if needed at the time of reconstruction. We do not routinely use intraoperative lumbar drains. Intravenous cefuroxime and $10 \mathrm{mg}$ of dexamethasone are administered at the start of the operation.

\section{Endoscopic Endonasal Approach: Initial Sinonasal Access}

We use a 2-surgeon (a neurosurgeon and an otolaryngologist), 3- to 4-hand approach via binostril access, and both surgeons stand on the patient's right side. This dualsurgeon approach enables the use of bimanual microsurgical dissection techniques via binostril access. We typically start with a $30^{\circ}$ high-definition 4-mm-diameter, $18-\mathrm{cm}-$ length, rigid endoscope (Karl Storz), which we prefer over the $0^{\circ}$ endoscope, because the additional $30^{\circ}$ gives us a more versatile angled view in a multidirectional fashion by allowing us to rotate the endoscope toward the desired viewing target. This endoscope is particularly helpful for accessing a lower-lying odontoid that is positioned at or slightly below the level of the hard palate. In some instances, a $0^{\circ}$ endoscope is more favorable, particularly in cases of severe cranial settling in which the odontoid process is well above the level of the hard palate.

The middle and inferior turbinates and nasal septal mucosa are infiltrated with $1 \%$ lidocaine with 1:100,000 epinephrine solution. The middle and inferior turbinates are then lateralized with a Goldman septum elevator to increase the endonasal working corridor bilaterally. We then perform a mucosa-sparing posterior septectomy to maximize the working corridor so that instruments introduced through both nostrils (binostril technique) can be triangulated at the surgical target (odontoid process). A right-sided pedicled nasoseptal flap (PNSF) based on the posterior septal branch of the sphenopalatine artery is elevated in a submucoperichondrial and submucoperiosteal fashion. The PNSF is then tucked into the ipsilateral middle meatus for protection, and the vascular pedicle is maintained in a safe location superior to the level of the choana. The same maneuver is repeated on the left side, and to prevent making the incisions directly opposite each other, care is taken to harvest a different-sized PNSF so that the septal incisions on both sides are offset. After elevating both PNSFs, the posterior bony septum is then resected. The size of the flaps and extent of the septectomy are determined largely by the expected size and location of the surgical defect and by the amount of space necessary for adequate triangulation of the instruments.

The surgical working corridor and access to the cranio- 
vertebral junction is primarily through the choanae bilaterally. The eustachian tubes, which represent the lateral limits of the approach, are identified bilaterally. ${ }^{38}$ The 2 eustachian tubes serve as useful landmarks for identifying the midline of the posterior pharyngeal wall centrally. The anatomical midline over the tubercle of C-1 is localized and confirmed with stereotactic image guidance. A longitudinal midline incision is made carefully over the posterior pharyngeal mucosal wall over the $\mathrm{C}-1$ tubercle by using a shielded monopolar cautery (Fig. 3A). The incision is carried through the mucosa along the midline raphe between the pharyngeal muscles and through the anterior longitudinal ligament down to the bone of $\mathrm{C}-1$. The monopolar cautery tip is slightly bent to the shape of a hockey stick and used to elevate the ligaments and mobilize the longus colli and longus capitis muscles laterally from the bone in a subperiosteal fashion. The incision is extended vertically so that exposure extends from the inferior clivus superiorly down to the C-2 vertebral body inferiorly. In some cases of platybasia, it may be necessary to perform a sphenoidotomy and extend the midline mucosal incision from the floor of the sphenoid sinus down to the inferior clivus. This process enables access to remove the floor of the sphenoid sinus to gain better access to the inferior clivus, especially if the odontoid process is situated in a retroclival position. The exposure of the bony elements is then widened by removal of the soft tissues with a tissue microdebrider and Tru-Cut rongeurs. It is important to clear all soft tissues off of the anterior arch of $\mathrm{C}-1$ and the odontoid process before removing these bony elements (Fig. 3B). Care is taken to avoid injury to the carotid arteries when dissecting laterally. Intraoperative CT angiogram-based image guidance and intraoperative micro-Doppler probes are useful adjuncts for avoiding this injury.

\section{Endoscopic Endonasal Odontoidectomy and Ventral Decompression}

The anterior arch of $\mathrm{C}-1$ is removed with a slightly curved endonasal high-speed cutting drill with self-irrigation (Fig. 4A). Additional irrigation with a double-barreled suction-irrigator is very helpful in clearing the surgical field of bone dust, cooling the drill tip, and rinsing tissue debris off of the endoscope lens. The arch of C-1 is drilled down by using the eggshell technique so that the remaining bone can be readily removed with angled curettes and Kerrison rongeurs. It is important that the extent of C-1 arch removal provides adequate access to the lateral edges and neck of the odontoid process. Care is taken to avoid drilling too laterally into the lateral masses of C-1.

Before performing the odontoidectomy, it is important to clearly define the edges of the odontoid process and to free them from any ligamentous attachments. The apical and alar ligaments can be detached from the odontoid with sharp straight and angled curettes. In patients with atlantoaxial instability, there may be a soft-tissue pannus situated in the atlantodental interval space that needs to be removed to better delineate the odontoid process. The center of the odontoid process is then hollowed out by using a high-speed endonasal drill with copious irrigation, leaving an eggshell-thin layer of outer cortical bone (Figs. $3 \mathrm{C}$ and $4 \mathrm{~B}$ ). The remaining eggshell-thin bone is then removed with angled dissectors (Rhoton 3 dissector), upangled 4-0 or 5-0 curettes, and Kerrison rongeurs (Fig. 3D). To avoid upward retraction of the odontoid tip toward the clivus, it is important to not prematurely transect the odontoid at its base..$^{30}$

After removal of the $\mathrm{C}-1$ arch and odontoid process, attention is now directed toward resecting the transverse
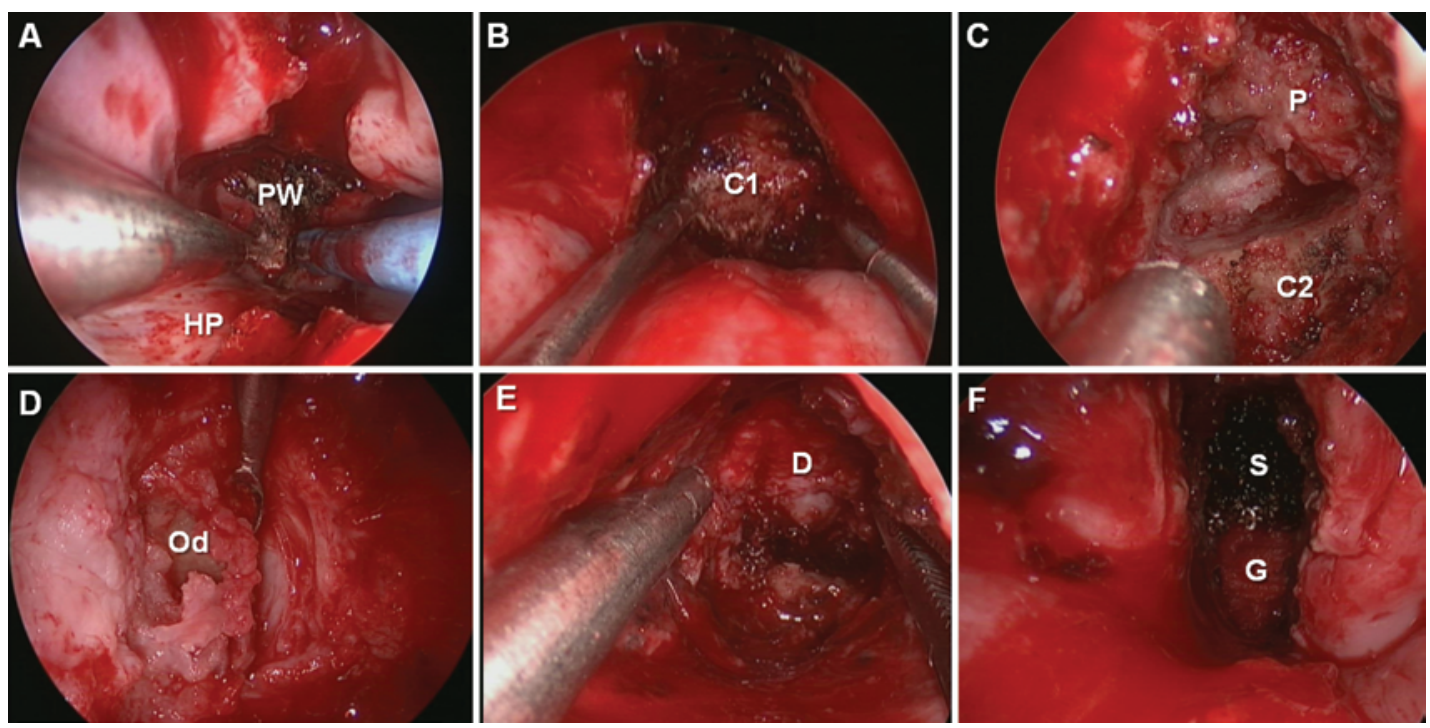

FIG. 3. Case 1. Intraoperative endoscopic photographs (see Figs. $1 \mathrm{~A}$ and 5). A: A midline incision is made in the posterior pharyngeal wall $(\mathrm{PW})$ using a monopolar cautery. HP = hard palate. B: The anterior arch of C-1 is exposed. C: After removal of the arch of $\mathrm{C}-1$, the odontoid process is hollowed out with a high-speed drill, leaving an eggshell remnant. The soft-tissue pannus $(P)$ is seen compressing the cervicomedullary junction. D: An up-angled curette is used to dissect the eggshell remnants and adherent pannus off of the craniocervical dura. Od = odontoid process. E: Final view of the dural sac (D) that has reinflated after adequate decompression. F: In the absence of an intraoperative CSF leak, the surgical defect is lined with Surgicel (S) and Gelfoam (G). 

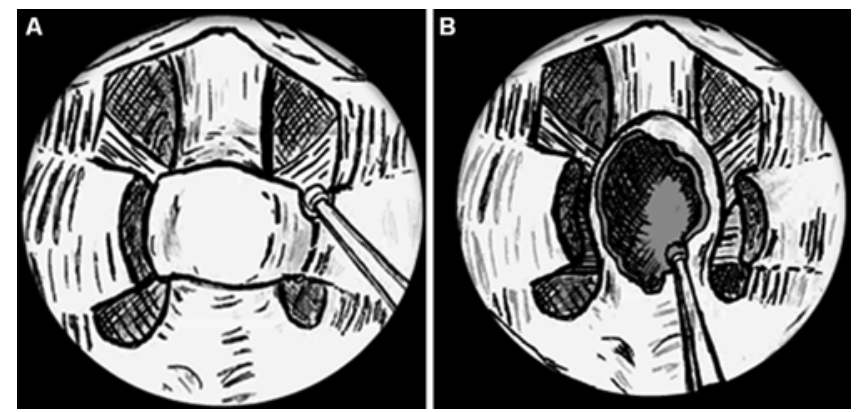

FIG. 4. Illustration of an endoscopic view of removal of the C-1 arch (A) followed by removal of the odontoid process (B). Copyright Jean Anderson Eloy. Published with permission.

ligament, tectorial membrane, and any residual ligaments to remove any compressive pannus. The underlying compressive pathology is removed to decompress the dura mater of the craniovertebral junction. In some cases, ligamentous or inflammatory tissue, or the posterior cortex of the odontoid, may be adherent to the dura mater. In such cases, it is important to leave a small remnant of adherent tissue or small "islands" of adherent bone while adequately debulking the thecal sac. We typically look for reinflation of the thecal sac with pulsations of the underlying cerebrospinal fluid (CSF) to assess the adequacy of decompression (Fig. 3E). Image guidance is also helpful in determining the extent of ventral decompression. In some cases of severe basilar invagination in which the odontoid tip is situated in a retroclival position, it is necessary to drill off the inferior clivus to access the odontoid. The clival dura tends to be thinner and more vulnerable to iatrogenic durotomy than the craniocervical junction dura. As such, we recommend a careful eggshell-drilling technique with a high-speed diamond bur to avoid dural tears and intraoperative CSF leakage. During ventral decompression of the cervicomedullary junction, the patient's mean arterial pressure is kept at $>85 \mathrm{~mm} \mathrm{Hg}$ to safely maintain spinal cord perfusion.

\section{Reconstruction and Closure}

The surgical cavity is inspected carefully, and meticulous hemostasis is achieved to avoid any compressive postoperative hematomas. If there is no evidence of intraoperative CSF leakage, the thecal sac and surgical cavity are lined with Surgicel, and gentamicin-soaked Gelfoam pledgets are placed into the odontoidectomy dead space (Fig. 3F). It is generally not necessary to close the midline pharyngeal mucosal incision, because this area readily undergoes mucosalization. ${ }^{51}$ Alternatively, a free mucosal graft harvested from the middle turbinate or hard palate can be used as an onlay graft, if one chooses to do so. In the absence of an intraoperative CSF leak, the bilateral PNSFs are returned to their native positions and secured in place with absorbable sutures that are run in a quilting pattern. This mucosa-sparing septectomy technique allows preservation of the mucosal integrity of the posterior nasal septum and salvages a reconstructive option for future usage.

If, however, an intraoperative CSF leak is present at the time of closure, it is necessary to repair the dural defect using a multilayered reconstruction with a vascularized PNSF. For small dural defects, we generally prefer to plug the durotomy with an autologous fat graft followed by a fascia lata onlay graft. The odontoidectomy dead space is packed gently with a fat graft to bolster the repair. Finally, 1 of the 2 PNSFs that were harvested earlier at the start of the surgery is rotated to cover the defect and buttressed with Surgicel, gentamicin-soaked Gelfoam pledgets and an expandable Merocel nasal tampon. The contralateral PNSF is returned to its native position and secured with an absorbable suture. Postoperative lumbar drainage is used for approximately 3 days at 5-10 $\mathrm{ml} /$ hour.

\section{Postoperative Management}

After closure, a flexible small-bore nasogastric feeding tube (Dobhoff tube) is placed under direct endoscopic visualization. Placement under direct visualization prevents passage of the tube into the surgical defect. The position of the tip within the stomach is confirmed with intraoperative C-arm fluoroscopic guidance. The tube is secured to the nasal septum and columella with a $2-0$ silk stitch to prevent migration. The patient is kept intubated postoperatively until after the occipitocervical stabilization and fusion procedure, which is performed at a second stage within 48 hours. During this period of intubation, the patient is fed enterally via the Dobhoff tube. After extubation, the patient is started on clear fluids and later advanced to a mechanical soft diet, as tolerated, and the Dobhoff tube is removed. The patient is kept on intravenous antibiotics and transitioned to oral antibiotics until the nasal packing is removed in the office 10-12 days postoperatively. Postoperative CT and MRI scans are obtained to assess the adequacy of cervicomedullary junction decompression and to assess the fixation of the occipitocervical stabilization (Fig. 5).

\section{Discussion}

Traditionally, anterior surgery to the craniovertebral junction has been approached via microsurgical transoral approaches or extended modifications (e.g., an extended transmaxillary, maxillary split, transpalatal, or transmandibular approach). $8,10,20,30,35,36,39,47$ These approaches are considered the gold standard and offer direct midline access and a wide operative field for decompressing lesions that affect the ventral cervicomedullary junction. However, these approaches have risks of complications such as phonation dysfunction and velopharyngeal insufficiency resulting from palatal division, cosmetic deformity from disarticulation of the facial skeleton (transmaxillary, transmandibular), prolonged tongue swelling and intubation requiring tracheostomy, and swallowing difficulty requiring gastrostomy. In addition, exposure of the pharyngeal incision to the oral flora and saliva may increase the risk of bacterial infection. ${ }^{51}$ Also, the microsurgical field of view is limited by the aperture of the mouth when the transoral approach is used. Thus, patients with micrognathia and/or macroglossia may not be feasible candidates for the transoral approach. ${ }^{28,32,33}$

More recently in the last decade, the endoscopic endonasal approach to the craniovertebral junction has gained 

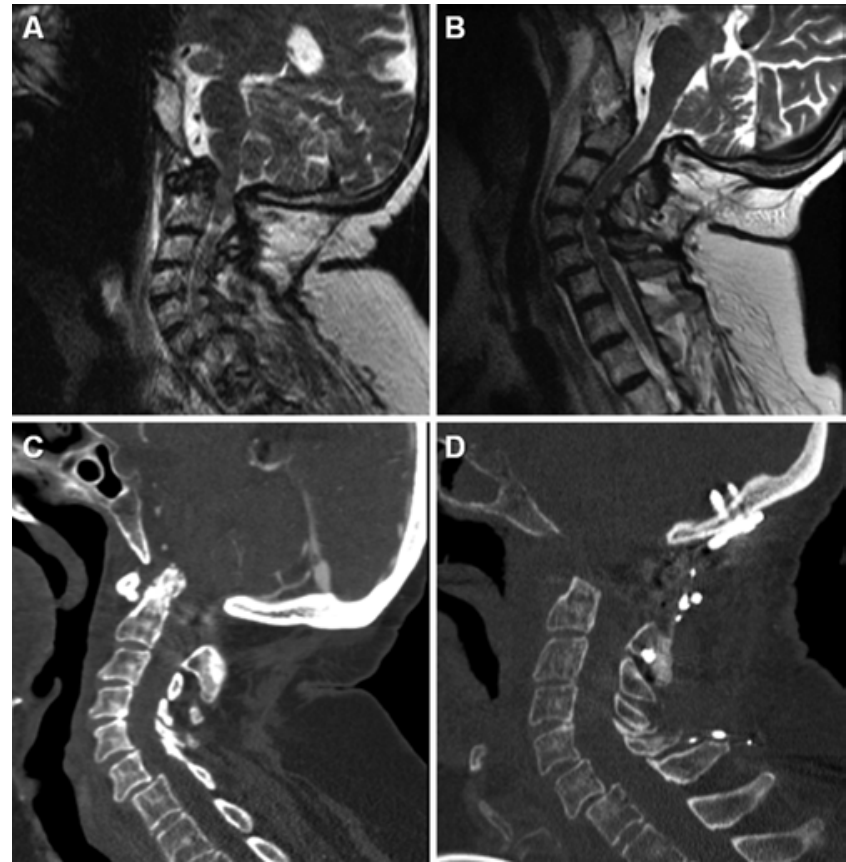

FIG. 5. Case 1. A and C: Preoperative sagittal T2-weighted MR and CT images, respectively, obtained in a patient with basilar invagination from rheumatoid arthritis. Surgery via the endoscopic endonasal transclival transodontoid approach was performed to decompress the cervicomedullary junction, followed by occipitocervical stabilization and fusion. B and D: Postoperative sagittal T2-weighted MR and CT images, respectively, showing excellent decompression of the cervicomedullary junction with restoration of the CSF signal at the foramen magnum.

increased popularity as a minimally invasive alternative to the standard transoral approaches. ${ }^{2,4,6,14,18,23,24,28,32,33,38,40-46,48}$ Alfieri et al. ${ }^{2}$ demonstrated the feasibility of endoscopic endonasal odontoidectomy in cadaveric studies in 2002, and Kassam et al. ${ }^{24}$ reported the first successful clinical application of this approach in a 73-year-old woman with rheumatoid arthritis and cervicomedullary compression. The endoscope offers panoramic visualization as well as increased illumination to deeper surgical targets. The endonasal route is very suitable for cases of significant basilar invagination in which the odontoid process is well above the palatine line. These pathologies are more difficult to access with a standard transoral approach and may require transpalatal or transmaxillary extensions, which increases the risk of morbidity.

In the endonasal route, the higher position of the mucosal incision in the nasopharynx, rather than in the oropharynx, theoretically lessens the risk of bacterial contamination by avoiding the oral cavity. ${ }^{18,24,51}$ In addition, earlier extubation and oral feeding seem to be important advantages gained with the endonasal approach. In a recent report of 9 patients who underwent endoscopic endonasal odontoidectomy by Goldschlager et al. ${ }^{18}$ the mean times to extubation and oral feeding were on postoperative Days 0.3 and 1, respectively. There were no instances of breathing or swallowing complications or velopharyngeal insufficiency. In another report of 12 patients who underwent odontoidectomy via either the endonasal or transoral route by Ponce-Gomez et al., ${ }^{43}$ the transoral group had a higher rate of postoperative dysphagia and dysphonia, whereas the endonasal group had lower times to extubation and oral feeding, shorter hospital stays, and no complications. It has been postulated that lower rates of postoperative dysphagia after endonasal odontoidectomy may be related to limiting the pharyngeal incision above the palatine line, thereby avoiding injury to the high-density neural plexus in the oropharyngeal wall and musculature, which is involved in swallowing. 49

Some limitations of the endoscopic endonasal approach include the relatively smaller operative field and a longer and narrower working corridor. The endonasal working corridor is limited laterally by the Eustachian tubes, superiorly by the nasal bones and nasal soft tissues, and inferiorly by the soft and hard palates. If the compressive lesion is situated more inferiorly below the palatine line and beyond the reach of the nasoaxial line, a transoral approach (endoscopic or microscopic) used alone or in conjunction with the endonasal approach may be warranted. The endoscopic endonasal technique requires a longer learning curve and experience in collaborating with otolaryngologists. The lack of depth perception with 2D endoscopes may be more evident in less-experienced endoscopic surgeons. Thus, the use of 3D endoscopes may speed up the learning curve. However, in our opinion, current 3D-endoscope technology does not surpass the picture quality and color clarity of current 2D high-definition endoscope systems. The lack of 3D depth perception can be readily overcome with dynamic movement of the $2 \mathrm{D}$ endoscope and by using tactile anatomical cues. Although once thought to be difficult to repair with an endoscopic endonasal approach, the presence of an intraoperative CSF leakage can be readily repaired by using multilayered reconstruction with a vascularized PNSF. 19,25,31

Another extraoral endoscopic alternative is the endoscopic transcervical approach, initially performed on 3 patients by Wolinsky et al. ${ }^{50}$ in 2007, which was followed up by a larger series of 15 patients in 2012..1 This endoscopic approach uses the same trajectory and retractor that are used for transcervical anterior odontoid screw fixation. It provides the advantage of avoiding bacterial contamination from exposure to the oral cavity and preserves the integrity of the pharyngeal mucosa. However, limitations include the longer working distance and the technical difficulty in performing this procedure in patients with a barrel-shaped chest or cervical kyphosis.

\section{Conclusions}

Anterior odontoidectomy and ventral decompression of the craniocervical junction can be achieved via 3 different operative corridors: transoral, endonasal, and transcervical (Fig. 6). ${ }^{4,51}$ The choice of the optimal surgical approach will be determined largely by the location of the pathology relative to the palatine line and the surgeon's preference and experience. In some instances, combined approaches or extended modification of an existing approach may be necessary depending on the extent of pathology. It is important for craniovertebral junction surgeons to have knowledge of all the potential approaches in their armamentarium and to individualize treatment strategies for each patient. 

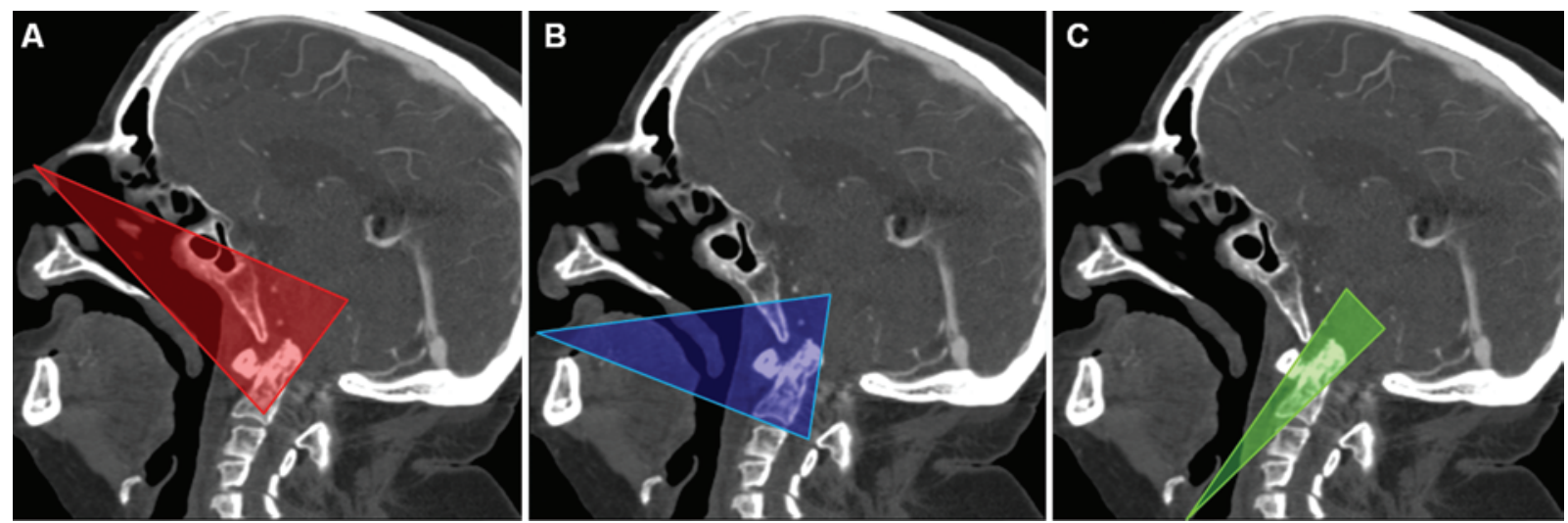

FIG. 6. Schematic illustration showing the different trajectories and zones of exposure via the endonasal (A), transoral (B), and transcervical (C) approaches in a patient with basilar invagination.

\section{References}

1. Aldana PR, Naseri I, La Corte E: The naso-axial line: a new method of accurately predicting the inferior limit of the endoscopic endonasal approach to the craniovertebral junction. Neurosurgery 71 (2 Suppl Operative):ons308-ons314, 2012

2. Alfieri A, Jho HD, Tschabitscher M: Endoscopic endonasal approach to the ventral cranio-cervical junction: anatomical study. Acta Neurochir (Wien) 144:219-225, 2002

3. Apuzzo ML, Weiss MH, Heiden JS: Transoral exposure of the atlantoaxial region. Neurosurgery 3:201-207, 1978

4. Baird CJ, Conway JE, Sciubba DM, Prevedello DM, Quiñones-Hinojosa A, Kassam AB: Radiographic and anatomic basis of endoscopic anterior craniocervical decompression: a comparison of endonasal, transoral, and transcervical approaches. Neurosurgery 65 (6 Suppl):158-164, 2009

5. Choi D, Crockard HA: Evolution of transoral surgery: three decades of change in patients, pathologies, and indications. Neurosurgery 73:296-304, 2013

6. Choudhri O, Mindea SA, Feroze A, Soudry E, Chang SD, Nayak JV: Experience with intraoperative navigation and imaging during endoscopic transnasal spinal approaches to the foramen magnum and odontoid. Neurosurg Focus 36(3):E4, 2014

7. Crockard HA: The transoral approach to the base of the brain and upper cervical cord. Ann R Coll Surg Engl 67:321-325, 1985

8. Crockard HA: Transoral surgery: some lessons learned. Br J Neurosurg 9:283-293, 1995

9. Crockard HA, Calder I, Ransford AO: One-stage transoral decompression and posterior fixation in rheumatoid atlantoaxial subluxation. J Bone Joint Surg Br 72:682-685, 1990

10. Crockard HA, Pozo JL, Ransford AO, Stevens JM, Kendall BE, Essigman WK: Transoral decompression and posterior fusion for rheumatoid atlanto-axial subluxation. J Bone Joint Surg Br 68:350-356, 1986

11. Dasenbrock HH, Clarke MJ, Bydon A, Sciubba DM, Witham TF, Gokaslan ZL, et al: Endoscopic image-guided transcervical odontoidectomy: outcomes of 15 patients with basilar invagination. Neurosurgery 70:351-360, 2012

12. de Almeida JR, Zanation AM, Snyderman CH, Carrau RL, Prevedello DM, Gardner PA, et al: Defining the nasopalatine line: the limit for endonasal surgery of the spine. Laryngoscope 119:239-244, 2009

13. Dickman CA, Kalani MY: Resolution of cervical syringomyelia after transoral odontoidectomy and occipitocervical fusion in a patient with basilar invagination and Type I Chiari malformation. J Clin Neurosci 19:1726-1728, 2012

14. Duntze J, Eap C, Kleiber JC, Théret E, Dufour H, Fuentes S, et al: Advantages and limitations of endoscopic endonasal odontoidectomy. A series of nine cases. Orthop Traumatol Surg Res 100:775-778, 2014

15. El-Sayed IH, Wu JC, Dhillon N, Ames CP, Mummaneni P: The importance of platybasia and the palatine line in patient selection for endonasal surgery of the craniocervical junction: a radiographic study of 12 patients. World Neurosurg 76:183-188, 2011

16. Goel A: Treatment of basilar invagination by atlantoaxial joint distraction and direct lateral mass fixation. J Neurosurg Spine 1:281-286, 2004

17. Goel A, Bhatjiwale M, Desai K: Basilar invagination: a study based on 190 surgically treated patients. J Neurosurg 88:962-968, 1998

18. Goldschlager T, Härtl R, Greenfield JP, Anand VK, Schwartz TH: The endoscopic endonasal approach to the odontoid and its impact on early extubation and feeding. J Neurosurg Spine 1:281-286, 2014

19. Hadad G, Bassagasteguy L, Carrau RL, Mataza JC, Kassam A, Snyderman $\mathrm{CH}$, et al: A novel reconstructive technique after endoscopic expanded endonasal approaches: vascular pedicle nasoseptal flap. Laryngoscope 116:1882-1886, 2006

20. Hadley MN, Spetzler RF, Sonntag VKH: The transoral approach to the superior cervical spine. A review of 53 cases of extradural cervicomedullary compression. J Neurosurg 71:16-23, 1989

21. Hankinson TC, Grunstein E, Gardner P, Spinks TJ, Anderson RC: Transnasal odontoid resection followed by posterior decompression and occipitocervical fusion in children with Chiari malformation Type I and ventral brainstem compression. J Neurosurg Pediatr 5:549-553, 2010

22. Hansen MA, da Cruz MJ, Owler BK: Endoscopic transnasal decompression for management of basilar invagination in osteogenesis imperfecta. J Neurosurg Spine 9:354-357, 2008

23. Iacoangeli M, Gladi M, Alvaro L, Di Rienzo A, Specchia N, Scerrati M: Endoscopic endonasal odontoidectomy with anterior $\mathrm{C} 1$ arch preservation in elderly patients affected by rheumatoid arthritis. Spine J 13:542-548, 2013

24. Kassam AB, Snyderman C, Gardner P, Carrau R, Spiro R: The expanded endonasal approach: a fully endoscopic transnasal approach and resection of the odontoid process: technical case report. Neurosurgery 57:E213, 2005

25. Kassam AB, Thomas A, Carrau RL, Snyderman CH, Vescan A, Prevedello D, et al: Endoscopic reconstruction of the cranial base using a pedicled nasoseptal flap. Neurosurgery 63:ONS44-ONS53, 2008

26. Klekamp J: Treatment of basilar invagination. Eur Spine J 23:1656-1665, 2014

27. Kyoshima K, Kakizawa Y, Tokushige K, Akaishi K, Kanaji M, Kuroyanagi T: Odontoid compression of the brainstem 
without basilar impression - "odontoid invagination." J Clin Neurosci 12:565-569, 2005

28. Laufer I, Greenfield JP, Anand VK, Härtl R, Schwartz TH: Endonasal endoscopic resection of the odontoid process in a nonachondroplastic dwarf with juvenile rheumatoid arthritis: feasibility of the approach and utility of the intraoperative Iso-C three-dimensional navigation. Case report. J Neurosurg Spine 8:376-380, 2008

29. Leng LZ, Anand VK, Hartl R, Schwartz TH: Endonasal endoscopic resection of an os odontoideum to decompress the cervicomedullary junction: a minimal access surgical technique. Spine (Phila Pa 1976) 34:E139-E143, 2009

30. Liu JK, Couldwell WT, Apfelbaum RI: Transoral approach and extended modifications for lesions of the ventral foramen magnum and craniovertebral junction. Skull Base 18:151166,2008

31. Liu JK, Schmidt RF, Choudhry OJ, Shukla PA, Eloy JA: Surgical nuances for nasoseptal flap reconstruction of cranial base defects with high-flow cerebrospinal fluid leaks after endoscopic skull base surgery. Neurosurg Focus 32(6):E7, 2012

32. Magrini S, Pasquini E, Mazzatenta D, Mascari C, Galassi E, Frank G: Endoscopic endonasal odontoidectomy in a patient affected by Down syndrome: technical case report. Neurosurgery 63:E373-E374, 2008

33. Mazzatenta D, Zoli M, Mascari C, Pasquini E, Frank G: Endoscopic endonasal odontoidectomy: clinical series. Spine (Phila Pa 1976) 39:846-853, 2014

34. McGirt MJ, Attenello FJ, Sciubba DM, Gokaslan ZL, Wolinsky JP: Endoscopic transcervical odontoidectomy for pediatric basilar invagination and cranial settling. Report of 4 cases. J Neurosurg Pediatr 1:337-342, 2008

35. Menezes AH: Surgical approaches: postoperative care and complications "transoral-transpalatopharyngeal approach to the craniocervical junction." Childs Nerv Syst 24:11871193,2008

36. Menezes AH, VanGilder JC: Transoral-transpharyngeal approach to the anterior craniocervical junction. Ten-year experience with 72 patients. J Neurosurg 69:895-903, 1988

37. Menezes AH, VanGilder JC, Clark CR, el-Khoury G: Odontoid upward migration in rheumatoid arthritis. An analysis of 45 patients with "cranial settling." J Neurosurg 63:500-509, 1985

38. Messina A, Bruno MC, Decq P, Coste A, Cavallo LM, de Divittis E, et al: Pure endoscopic endonasal odontoidectomy: anatomical study. Neurosurg Rev 30:189-194, 2007

39. Mummaneni PV, Haid RW: Transoral odontoidectomy. Neurosurgery 56:1045-1050, 2005

40. Nayak JV, Gardner PA, Vescan AD, Carrau RL, Kassam AB, Snyderman CH: Experience with the expanded endonasal approach for resection of the odontoid process in rheumatoid disease. Am J Rhinol 21:601-606, 2007

41. Patel AJ, Boatey J, Muns J, Bollo RJ, Whitehead WE, Giannoni CM, et al: Endoscopic endonasal odontoidectomy in a child with chronic type 3 atlantoaxial rotatory fixation: case report and literature review. Childs Nerv Syst 28:19711975,2012

42. Pillai P, Baig MN, Karas CS, Ammirati M: Endoscopic image-guided transoral approach to the craniovertebral junction: an anatomic study comparing surgical exposure and surgical freedom obtained with the endoscope and the operating microscope. Neurosurgery 64 (5 Suppl 2):437-444, 2009

43. Ponce-Gómez JA, Ortega-Porcayo LA, Soriano-Barón HE, Sotomayor-González A, Arriada-Mendicoa N, GómezAmador JL, et al: Evolution from microscopic transoral to endoscopic endonasal odontoidectomy. Neurosurg Focus 37(4):E15, 2014

44. Qiuhang Z, Feng K, Bo Y, Hongchuan G, Mingchu L, Ge $\mathrm{C}$, et al: Transoral endoscopic odontoidectomy to decompress the cervicomedullary junction. Spine (Phila Pa 1976) 38:E901-E906, 2013

45. Rawal RB, Shah RN, Zanation AM: Endonasal odontoidectomy for basilar impression and brainstem compression due to radiation fibrosis. Laryngoscope 123:584-587, 2013

46. Singh H, Grobelny BT, Harrop J, Rosen M, Lober RM, Evans $\mathrm{J}$ : Endonasal access to the upper cervical spine, part one: radiographic morphometric analysis. J Neurol Surg B Skull Base 74:176-184, 2013

47. Spetzler RF, Hadley MN, Sonntag VK: The transoral approach to the anterior superior cervical spine. A review of 29 cases. Acta Neurochir Suppl (Wien) 43:69-74, 1988

48. Tanriverdi O, Tugcu B, Gunaldi O, Baydin SS, Demirgil BT, Sam B, et al: The selective odontoidectomy: endoscopic endonasal approach to the craniocervical junction. J Craniofac Surg 25:1482-1487, 2014

49. Van Abel KM, Mallory GW, Kasperbauer JL, Moore EJ, Price DL, O'Brien EK, et al: Transnasal odontoid resection: is there an anatomic explanation for differing swallowing outcomes? Neurosurg Focus 37(4):E16, 2014

50. Wolinsky JP, Sciubba DM, Suk I, Gokaslan ZL: Endoscopic image-guided odontoidectomy for decompression of basilar invagination via a standard anterior cervical approach. Technical note. J Neurosurg Spine 6:184-191, 2007

51. Wu JC, Huang WC, Cheng H, Liang ML, Ho CY, Wong TT, et al: Endoscopic transnasal transclival odontoidectomy: a new approach to decompression: technical case report. Neurosurgery 63:ONSE92-ONSE94, 2008

52. Yu Y, Hu F, Zhang X, Ge J, Sun C: Endoscopic transnasal odontoidectomy combined with posterior reduction to treat basilar invagination. Technical note. J Neurosurg Spine 19:637-643, 2013

53. Yu Y, Wang X, Zhang X, Hu F, Gu Y, Xie T, et al: Endoscopic transnasal odontoidectomy to treat basilar invagination with congenital osseous malformations. Eur Spine J 22:1127-1136, 2013

\section{Author Contributions}

Conception and design: Liu, Eloy. Acquisition of data: Liu, Patel. Analysis and interpretation of data: Liu. Drafting the article: Liu. Critically revising the article: all authors. Reviewed submitted version of manuscript: all authors. Approved the final version of the manuscript on behalf of all authors: Liu. Administrative/technical/material support: Patel, Eloy. Study supervision: Liu, Eloy.

\section{Correspondence}

James K. Liu, Department of Neurological Surgery, Neurological Institute of New Jersey, Rutgers New Jersey Medical School, Newark, NJ 07103. email: james.liu.md@rutgers.edu. 